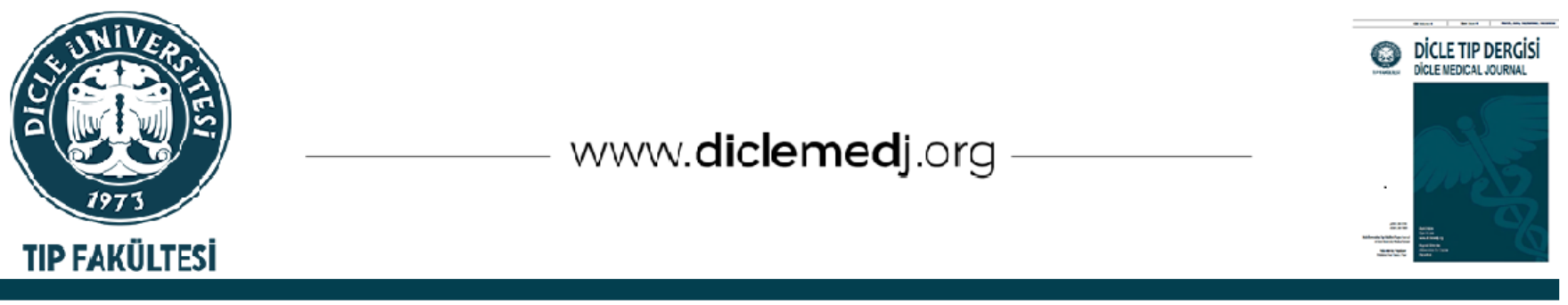

Özgün Araştırma / Original Article

\title{
Acil Servise Başvuran İnme Olgularında Laktat ve Laktat Klirensinin Mortalite Üzerine Etkileri
}

\author{
Murat Orak ${ }^{1}$, Mustafa İpek ${ }^{2}{ }^{2}$, Mehmet Üstündağ ${ }^{1}{ }^{1}$, Mahmut Yaman ${ }^{1}{ }^{1}$, Mehmet Ufuk Aluçlu ${ }^{3}$, \\ Cahfer Güloğlu iD 1
}

1 Dicle Üniversitesi Tıp Fakültesi, Acil Tıp Anabilim Dalı, Diyarbakır, Türkiye

2 Siverek Devlet Hastanesi, Acil Servisi, Şanlıurfa, Türkiye

3 Dicle Üniversitesi Tıp Fakültesi, Nöroloji Anabilim Dal, Diyarbakır, Türkiye

Geliş: 25.05.2021; Revizyon: 08.08.2021; Kabul Tarihi: 09.08.2021

Öz

Amaç: İskemik ve hemorajik serebrovasküler hastalıklar, önemli bir morbidite ve mortalite nedenidir. Laktat klirensinin kritik hasta grubunda tüm mortaliteler ile ilişkili olduğu gösterilmiş. Biz bu çalışmada kritik hasta grubu içinde olabilecek inme ön tanılı hastalarda laktat ve laktat klirensinin prognozu tayin etmede yerini araştırmayı amaçladık.

Yöntemler: 01.01.2018-31.12.2018 tarihleri arasında Dicle Üniversitesi acil servisine inme ön tanısıyla başvuran yaklaşık 300 hasta retrospektif olarak incelendi. Çalışma kriterlerine uyan 50 hastanın geliş anı laktat değeri, 24. saat laktat değeri ve 24. saat laktat klirensi değerlerine bakıldı. Çıkan sonuçların mortalite üzerine etkileri incelendi.

Bulgular: Çalışmaya 50 hasta dahil edildi. Bu hastaların 23'ü erkek, 27'si kadındı. Hastaların yaş ortalaması 64,18 \pm 17.80 yıl olarak hesaplandı. Ölen hastaların 6'sı erkek, 13'ü kadın olup yaş ortalaması 66.11£19.95 yıl idi. Sağ kalan ve ölen hastalarımızın laktat düzeyleri ve laktat klirenslerine göre değerlendirildiğinde ölen hastalarımızda 24'üncü saatteki laktat düzeyi anlamlı derecede yüksektir

Sonuç: İnme ön tanısıyla acile başvuran hastalarda laktat klirensinin prognoz tayini açısından iyi bir marker olamayacağı, 24. Saat laktat değerinin daha anlamlı olduğu ortaya çıktı.

Anahtar kelimeler: Laktat, laktat klirensi, inme, acil servis, prognoz

DOI: 10.5798/dicletip.

Correspondence / Yazışma Adresi: Mahmut Yaman, Kıtılbil Mah. Dicle Üniversitesi Acil Tıp Anabilim Dalı Sur/ Diyarbakır, Türkiye Posta Kodu: 21200 email:drmahmutyaman@hotmail.com 


\title{
The Effects of Lactate And Lactate Clearance On Mortality of Stroke Cases Who Admitted To Emergency Department
}

\begin{abstract}
Objective: Ischemic and hemorrhagic cerebrovascular diseases are an important cause of morbidity and mortality. Lactate clearance has been shown to be associated with all mortalities in the critically ill group. In this study, we aimed to investigate the role of lactate and lactate clearance in determining the prognosis in patients with pre-diagnosis of stroke who may be in the critically ill group.

Methods: Approximately 300 patients were retrospectively analyzed who applied to the Dicle University emergency service with a pre-diagnosis of stroke between 01.01.2018 and 31.12.2018. The lactate level at the time of admission, lactate level at the 24th hour and lactate clearance at the 24th hour of the 50 patients who met the study criteria were evaluated. The effects of the results on mortality were examined.

Results: 50 patients were included in the study. 23 of these patients were men and 27 were women. The mean age of the patients was calculated as $64.18 \pm 17.80$ years. 6 of the patients who died were male and 13 were female, and the mean age was $66.11 \pm 19.95$ years. When evaluated according to the lactate levels and lactate clearance of our surviving and deceased patients, the lactate level at the 24th hour is significantly higher in our patients who died
\end{abstract}

Conclusion: It was revealed that lactate clearance is not a good marker for determining prognosis in patients admitted to the emergency service with a pre-diagnosis of stroke, and the 24 th hour lactate level is more significant.

Keywords: Lactate, lactate clearance, stroke, emergency department, prognosis.

\section{GİRIŞ}

Serebrovasküler hastalıklar, beyin bölgesinin kanama veya iskemi sonrası beynin kalıcı ya da geçici olarak etkilenmesi durumudur ${ }^{1}$. İnme ise Dünya Sağlık Örgütü kriterlerine göre, ani gelişen, 24 saatten fazla süren ya da bu süre içinde ölüm ile sonlanan, vasküler nedenden başka bir neden ortaya konulamayan ve fokal veya jeneralize nörolojik defisittir ${ }^{2}$. National Institute of Neurological Disorders and Stroke (NINDS) beyin damar hastalıklarını şöyle tanımlamaktadır: Beynin bir bölgesinin, kanama veya iskemi sonucu geçici ya da kalıcı olarak etkilenmesi ve/veya beyin içindeki bir ya da daha fazla kan damarının birincil patolojik hasarıdır ${ }^{3}$. Dünyada altmış yaş üstü popülasyonda koroner arter kaynaklı hastalıklardan sonra beyin damar kaynaklı hastalıklara bağlı ölüm oranı ikinci sırada yer almaktadır. Sakatlık ve işgücü kaybının ise birinci nedenidir4. Yapılan araştırmalar acil servise inmeyle gelen hastaların erken teşhis ve tedavisi ile bu hastalığın mortalite ve morbidite üzerine etkilerini azaltabileceğini göstermiştir ${ }^{5}$.

\section{İnme ikiye ayrılır:}

a- İskemik İnme: Sistemik hipoperfüzyon, emboli veya tromboz nedeniyle oluşur ve $\% 80$ oranında görülür.

b- Hemorajik İnme: Subaraknoid kanama veya İntraserebral kanama nedeniyle oluşur ve $\% 20$ oranında görülür6.

Eritrositler, perivenöz hepatositler, iskelet kası hücreleri ve ciltten laktat üretimi yapılır. Bazal üretilen laktat miktarı yaklaşı 0,8 $\mathrm{mmol} / \mathrm{kg} / \mathrm{saat}$ kadardır. Karaciğer laktatın \%70'ni detoksifiye eder. Laktat düzeyi oksijenizasyon ve perfüzyon yeterliliğinin, mikrosirküler fonksiyon bozukluğunun bütüncül bir göstergesi olarak kullanılmaktadır ${ }^{7}$.

Hiperlaktatemi (> $5 \mathrm{mmol} / \mathrm{L}$ ) Tip A (doku hipoksisi mevcut) ve Tip B (doku hipoksisi mevcut değil) olmak üzere ikiye ayrılmaktadır. Laktat üretiminin artması, hepatik laktat klirensinin azalması, kronik hastalıklar, sepsis, ekstrahepatik metabolizmanın azalması, 
böbreklerden atılımın azalması laktat düzeyinin yükselmesine sebep olabilir ${ }^{8}$.

Laktat klirensinin sepsis ve kalp durması dahil olmak üzere birçok kritik hasta popülasyonun izlenmesinde değerli olduğu bazı yayınlarda belirtilmektedir ${ }^{8}$. Laktat klirensinin klinik seyrin başlarında değerlendirilmesi, vücudun laktat üretimini belirleme ve tepki verme hızını belirler. Yapılan bazı çalışmalara göre laktat klirensinin çoğu ilk iki saatte gerçeleşir. Sonraki saatlerde ise laktat klirensi değeri özellikle 2 ile 4 . Saat arasında plato çizer ${ }^{9}$. Laktat klirensi $=[($ İlk laktat - Son laktat) / İlk laktat] x 100 ; Kontrol ölçümün en az 2 saat sonra yapılması gerektiği belirtiliyor ${ }^{10}$.

\section{YÖNTEMLER}

01.01.2018-31.12.2018 tarihleri arasında Dicle Üniversitesi Acil Servisine inme ön tanısıyla başvuran yaklaşık 300 hasta retrospektif olarak incelendi. Çalışma için Dicle Üniversitesi girişimsel olmayan klinik araştırmalar etik kurulundan 21.01.2019 tarih ve 70 sayı numaralı Etik Kurul onayı alındı. Çalışma kriterlerine uyan 50 hastanın geliş anı laktat değeri, 24. saat laktat değeri ve 24. saat laktat klirensi değerlerine bakıldı. Çıkan sonuçların mortalite üzerine etkileri incelendi.

Çalışmaya 15 yaş ve üzeri hastalar dahil edilmiş olup en az bir gün hastanede takipli olanlar değerlendirildi. Çalışmadan, eş zamanlı travma nedeniyle başvuran ve hastane otomasyon sistemine kayıt olmayan hastalar dışlandı. Çalışmaya dahil olan hastalar nöroloji servis, nöroloji yoğun bakım (YB) ve acil YB'da yatan hastalardan ele alındı. Diğer servis ve YB'daki hastaların paranörojenik ek patalojileri olduğundan ve inme tanıları yatıştan sonra gerçekleştiğinden çalışma dışı bırakıldı. Ayrıca laktat ve laktat klirensini etkileyebilecek kalp yetmezliği, sepsis, yanık, şok (kardiyojenik, septik, hemorajik ve nörojenik şok dahil) vs. bulguları veya tanıları olan hastalar çalışmaya dahil edilmedi. Çalışmaya izole serebrovasküler hastalık bulgusu olan hastalar dahil edildi. Laktat klirensi $=$ [(İlk laktat - Son laktat $) /$ İlk laktat $] \mathrm{x}$
100 olarak hesaplandı. Veriler Ortalama \pm Standart Sapma (SD) olarak ifade edildi. İstatistiksel analizde kategorik değişkenler icin Ki-kare ve sürekli değişkenler icin Student $t$ testleri kullanıldı. Çoklu grup karşılaştırmalarında One-Way Annova ve Post-hock Dunnet testi kullanılarak yapıldı ve $\mathrm{p}<0.05$ değeri anlamlı kabul edildi.

\section{BULGULAR}

Çalışmaya 50 hasta dahil edildi. Bu hastaların 23'ü erkek, 27'si kadındı. Hastaların yaş ortalaması $64,18 \pm 17.80$ yll olarak hesapland. Çalışmamızdaki să̆ kalan hastaların 17'si erkek, 14'ü kadın idi ve yaş ortalaması 63.00ะ16.59 yıl idi. Ölen hastaların 6'sı erkek, 13'ü kadın olup yaş ortalaması $66.11 \pm 19.95$ yll idi. Cinsiyet ve yaş açısından sağ kalan ile ölen hastalar arasında istatiksel olarak anlamlı fark bulunmadı (sırası ile $\mathrm{p}=0.148$ ve $\mathrm{p}=0.574)$. Sağ kalan ve ölen hastalarımızın laktat düzeyleri ve laktat klirensleri ortalamasına göre değerlendirildiğinde ölen hastalarımızda 24'üncü saatteki laktat düzeyi ortalaması anlamlı derecede yüksek bulunurken geliş laktat düzeyi ve laktat klirensi ortalaması ölen ve sağ kalan hastalarımızda anlamlı tespit edilmedi. (sırasıyla $p=0.009, p=0.172$ ve $p=0.557$ ). (Tablo I).

Tablo I: Sağ kalan ve ölen hastaların demografik verileri ve geliş laktat, 24. saatteki laktat düzeyi ve 24. saat laktat klirensine göre dağılımı

\begin{tabular}{|l|l|l|l|}
\hline & Sağ Kalan & Ölen & $\begin{array}{l}\mathrm{P} \\
\text { değeri }\end{array}$ \\
\hline Yaş & $63.00 \pm 16.59$ & $66.11 \pm 19.95$ & 0.574 \\
\hline Cinsiyet & & & \\
\hline Kadın & 17 & 6 & 0.148 \\
\hline Laktat Geliş & $2.08 \pm 2.53$ & $3.31 \pm 3.28$ & 0.172 \\
\hline $\begin{array}{l}\text { 24. Saat laktat } \\
\text { Klirensi }\end{array}$ & $1.45 \pm 0.77$ & $4.27 \pm 4.17$ & 0.009 \\
\hline Saat Laktat & $43.03 \pm 42.83$ & $36.47 \pm 34.82$ & 0.557 \\
\hline
\end{tabular}


Hastaların yattığı yere göre ilk laktat, 24.saat laktat değeri ve 24. Saat laktat klirensi değerlerinin karşılaştırılması yapıldığında 24.saat laktat değerleri YB'da yatan hastalarda klinikte yatan hastalara göre anlamlı derecede yüksek çıktı ( $\mathrm{P}=0.048)$. (Tablo II).

Hastaların geliş laktat, 24.saat laktat ve 24.saat laktat klirenslerinin hastaneden çıkış şekillerine göre kendi içinde karşılaştırılması yapıldığında; Ölen hastalar, şifa ile taburcu olanlar ile karşılaştırıldığında 24.saat laktat değerleri anlamlı derecede ölenlerde yüksek çıtı $(\mathrm{P}=0.006)$. Aynı şekilde ölen hastalarda, taraf bulgusu ile taburcu olanlara göre 24. Saat laktat değeri anlamlı derece yüksek çıktı $(\mathrm{P}=0.016)$. (Tablo III).

Tablo II: Klinik ve YB'da yatan hastaların ilk laktat, 24. Saat laktat ve 24. Saat laktat klirensinin karşılaştırılması

\begin{tabular}{|l|l|l|l|}
\hline \multicolumn{1}{|l|}{} & $\begin{array}{l}\text { Yatış klinik } \\
\mathrm{n}=17\end{array}$ & $\begin{array}{l}\text { Yatış YB } \\
\mathrm{n}=33\end{array}$ & P değeri \\
\hline İlk laktat & $2,64 \pm 3,32$ & $2,50 \pm 2,66$ & 0,881 \\
\hline $\begin{array}{l}\text { 24. saat } \\
\text { laktat }\end{array}$ & $1,64 \pm 0,98$ & $2,98 \pm 3,49$ & 0,048 \\
\hline $\begin{array}{l}\text { 24. saat } \\
\text { Laktat } \\
\text { klirensi }\end{array}$ & $44,16 \pm 32,11$ & $36,26 \pm 33,73$ & 0,424 \\
\hline
\end{tabular}

Tablo III: Hastaların ilk laktat, 24. Saat laktat ve 24. Saat laktat klirenslerine göre taburculuk (tbrc) şekillerinin kendi içinde karşılaştırılması

\begin{tabular}{|c|c|c|}
\hline & GRUPLAR & P değer \\
\hline İlk laktat & $\begin{array}{lc}\text { Ölen }(3,31 \pm 3,28) & \text { Şifa ile tbrc }(1,68 \pm 0,95) \\
& \text { Taraf ile tbrc }(2,50 \pm 3,52) \\
\text { Şifa ile tbrc }(1,68 \pm 0,95) & \text { Taraf ile tbrc }(2,50 \pm 3,52)\end{array}$ & $\begin{array}{l}0,296 \\
1,00 \\
1,00\end{array}$ \\
\hline 24. saat laktat & $\begin{array}{lc}\text { Ölen }(4,27 \pm 4,17) & \text { Sifa ile tbrc }(1,31 \pm 0,55) \\
& \text { Taraf ile tbrc }(1,60 \pm 0,95) \\
\text { Şifa ile tbrc }(1,31 \pm 0,55) & \text { Taraf ile tbrc }(1,60 \pm 0,95)\end{array}$ & $\begin{array}{l}0,006 \\
0,016 \\
1,00\end{array}$ \\
\hline 24. saat laktat klirensi & $\begin{array}{ll}\text { Ölen }(41,54 \pm 40,02) & \text { Şifa ile tbrc }(42,80 \pm 35,43) \\
& \text { Taraf ile tbrc }(31,55 \pm 18,44) \\
\text { Şifa ile tbrc }(42,80 \pm 35,43 & \text { Taraf ile tbrc }(31,55 \pm 18,44)\end{array}$ & $\begin{array}{r}1,00 \\
1,00 \\
1,00\end{array}$ \\
\hline
\end{tabular}

\section{TARTIŞMA}

Laktat düzeyi perfüzyon ve oksijenizasyon yeterliliğinin, mikrosirkulatuar fonksiyon bozukluğunun global bir göstergesi olarak kullanılmaktadır7. Son zamanlarda yapılan çalışmalarda iskemik ve hemorajik inme gibi stres durumlarında, anaerobik metabolizma sonucu ortaya çıkan laktatın beyin tarafından enerji kaynağı olarak kullanıldığı gösterilmiştir ${ }^{11}$.

Nedeni ne olursa olsun şok, mikrosirkülasyonda bozukluk, doku ve organlara oksijen iletiminin bozulması ve son olarak da organ fonksiyonunun bozulması ile karakterizedir. Derhal tersine çevrilmezse, hayati organlara sürekli zayıf perfüzyon, ölümün güçlü bir prediktörü olduğu iyi bilinen çoklu organ disfonksiyon sendromuna yol açacaktır. Önceki 
çalışmalarda gösterildiği üzere prokolize edilmiş, önceden tanımlanmış laktat klirensine ulaşmayı amaçlayan kantitatif resüsitasyon, laktat klirensi içermeyen geleneksel paketlere kıyasla daha iyi klinik sonuçlara yol açabilir ${ }^{12}$. Zhang Z, \& Xu X'in yaptı̆̆ bir sistematik review ve metaanalize göre laktat klirensinin kritik hasta grubunda tüm mortaliteler ile ilişkili olduğu gösterilmiş. Erken laktat klirensi, sağkalımın güçlü bir prediktörü ve laktattaki sürekli yükselme olumsuz klinik sonuçların habercisi olduğu belirtilmişs². Bizim çalışmamızda ise inme ön tanısıyla başvuran hastaların mortaliteyi öngörmede laktat klirensinin iyi bir marker olmadığı saptandı.

Zhou, Bao-Chun ve arkadaşları hastaların başvuru anındaki, 12.saatteki, 24. Saat ve sonraki laktat değerlerinin nörolojik sonuçları ile önemli derece ilişkisinin olduğunu tespit etmişler ${ }^{13}$. MontielJarquín, Álvaro ve arkadaşları, şok durumlarında 12.saat ve bilhassa 24. Saat laktat klirensinin belirlenmesinin mortaliteyi tahmin etmede önemli olduğunu tespit etmişler ${ }^{14}$. Bizim çalışmamızda ise hastaların 24. Saatteki lakat değerleri mortaliteyi öngörmede 24.saat laktat klirensinden daha değerli çıktı. Yine aynı şekilde çalışmamızda hastaların progresyonunu gösterecek bir gösterge olan yatış yerlerine bakıldığında, 24. Saat laktat değerleri YB'da yatan hastalarda serviste yatan hastalara göre anlaml derecede yüksek çıktı.

Caglayan ve arkadaşlarının iskemik ve hemorajik hastaların prognoz tayininde laktatın yeri ile ilgili yaptıkları çalışmada laktatın, alınan vaka örneklerine göre prognoz tayininde etkin bir laboratuvar parametresi olarak kullanımın faydalı olmayacağı tespit edilmiş ${ }^{15}$. Görmeli Kurt ve arkadaşları kronik obstrüktif akciğer hastalığı alevlenmesinde 6 saatlik takiple taburculuk ve hasta kabulü açısından laktat klirensinin önemli bir belirteç olduğunu tespit etmişler ${ }^{16}$. Emektar ve arkadaşlarının karbonmonoksit zehirlenmelerinde, serum laktat düzeyleri ve tedavinin etkinliğinin belirlenmesinde laktat klirenslerinin kullanılması ile ilgili yaptıkları çalışmada karbonmonoksit zehirlenmesinde laktat düzeyinin arttığını belirtmişler. Tedavinin etkinliğinin değerlendirilmesinde laktat klirensinin önemli bir rolü olduğunu tespit etmişler ${ }^{17}$. İbrahim ve arkadaşlarının diyabetik ketoasidozlu hastalarda yaptıkları çalışmada başvurudan 2 saat sonraki laktat klirensinin, 30 günlük mortaliteyi öngörmede anlamlı olduğu tespit edildi ${ }^{18}$. Fakat Fuernau ve arkadaşları kardiyojenik şoklu hastalarda 30 günlük mortaliteyi tahmin etmek için yaptıkları çalışmada 8 saat sonraki laktat değerinin başlangıç laktat ve laktat klirensine göre daha anlamlı olduğunu tespit etmişler ${ }^{19}$. Bizim çalışmamızda ise laktat klirensinden ziyade 24 . Saat laktat değeri hastaneden çıkış şekillerini belirlemede yardımcı oldu. Hastaların hastaneden çıkış şekilleri kendi arasında karşılaştırıldığında ölen hastalarda, taraf ve şifa ile taburcu olan hastalara göre 24. saat laktat değerlerinin anlamlı derecede arttığı tespit edildi.

\section{Kisitlamalar}

Çalışmamızın bazı sınırlamaları mevcut. Öncelikle bu çalışma tek merkezli ve retrospektif yapıldı. Çok merkezli ve prospektif yapılacak olan çalışmalar farklı sonuçlar verebilir. İkincil olarak hastaların takiplerinde uygun kan gazı takibi yapılmış örneklem büyüklüğü fazla olan hastalar ile sonuçlar farklılık gösterebilir. Üçüncül olarak da değerlendirilen hastalar arasında takibi uzun sürenler sonuçları etkilemektedir.

\section{SONUÇ}

Her ne kadar birçok çalışmada mortaliteyi öngörmede laktat klirensi iyi bir marker olsa da bizim çalışmamızda inme ön tanısıyla acile başvuran hastalarda laktat klirensinin prognoz tayini açısından iyi bir marker olamayacağı 24 . Saat laktat değerinin daha anlamlı olduğu ortaya çlktı.

Etik Kurul Kararı: Çalışma için Dicle Üniversitesi girişimsel olmayan klinik araştırmalar etik kurulundan 21.01.2019 tarih ve 70 sayı numaralı Etik Kurul onayı alındı.

Çıkar Çatışması Beyanı: Çıkar çatışması bulunmamaktadır. 
Finansal Destek: Bu çalışma her hangi bir fon tarafından desteklenmemiştir.

Declaration of Conflicting Interests: The author declare that she has no conflict of interest.

Financial Disclosure: No financial support was received.

\section{KAYNAKLAR}

1. Silvestrelli G, Paciaroni M, Caso V, et al. Risk Factors and Stroke Subtypes: Results of Five Consecutive Years of the Perugia Stroke Registry. Clin Exp Hypertens. 2006 Jan 3;28.

2. WHO MONICA Project Principal Invest. The world health organization monica project (monitoring trends and determinants in cardiovascular disease): A major international collaboration. J Clin Epidemiol. 1988;41.

3. Öztürk ZE, İntrakranial İnme Sonrası Saptanan Risk Faktörlerinin Morbidite ve Mortalite Üzerine Etkisi. [Uzmanlık Tezi] İstanbul: Dr. Lütfi Kırdar Kartal Eğitim ve Araştırma Hastanesi Nöroloji Kliniği; 2004.

4. Demirci Şahin A, Üstü Y, Işık D. Serebrovasküler Hastalıklarda Önlenebilen Risk Faktörlerinin Yönetimi. Ankara Med J. 2015 Apr 28;15.

5. Gürger M, Bozdemir MN, Yıldız M, et al. Acil Servise İskemik İnme Nedeniyle Başvuran Hastalarda Hastane İçi Mortalitenin Belirlenmesinde Kardiyak Belirteçlerin Rolü. Turk J Emerg Med 2008; 8: 59-66

6. Demirci Şahin A, Üstü Y, Işık D, Uğurlu M. Serebrovasküler Hastalık Geçiren Hastaların Demografik Özellikleri ve Birinci Basamak Sağlık Merkezlerinde Önlenebilen Risk Faktörlerinin Yönetimi. Ankara Med J. 2015 Nov 24; 15.

7. Levy B. Lactate and shock state: the metabolic view. Curr Opin Crit Care. 2006 Aug; 12.

8. Sargin G, Yavasoglu I, Kadikoylu G, Bolaman Z. Lactic Acidosis: A Short Review of Cases. Dahili ve Cerrahi Bilim Yoğun Bakım Dergisi/ Turkish J Med Surg Intensive Care. 2011 Dec 1; 2.

9. Jones AE. Lactate Clearance in the Acutely Traumatized Patient. Anesthesiology. 2012 Dec 1; 117.
10. Jones AE. Lactate Clearance vs Central Venous Oxygen Saturation as Goals of Early Sepsis Therapy\&lt;subtitle\&gt;A Randomized Clinical Trial\&lt;/subtitle\&gt; JAMA. 2010 Feb 24; 303.

11. Horn T, Klein J. Neuroprotective effects of lactate in brain ischemia: Dependence on anesthetic drugs. Neurochem Int. 2013 Feb; 62.

12. Zhang $\mathrm{Z}, \mathrm{Xu} \mathrm{X}$. Lactate Clearance Is a Useful Biomarker for the Prediction of All-Cause Mortality in Critically Ill Patients. Crit Care Med. 2014 Sep; 42.

13. Zhou B-C, Zhang Z, Zhu J-J, Liu L-J, Liu C-F. Blood Lactate or Lactate Clearance: Which Is Robust to Predict the Neurological Outcomes after Cardiac Arrest? A Systematic Review and Meta-Analysis. Biomed Res Int. 2018 Oct 2; 2018.

14. Montiel-Jarquín Á, Láscarez-Lagunas I, SánchezGasca C, et al. Lactate Clearance is a Prognostic Factor in Patients on Shock State. Electron J Gen Med. 2012 Apr 10; 9.

15. Çağlayan T, Özakın E, Özdemir A, et al. Hemorajik Ve İskemik Serebrovasküler Hastalık Tanısı Alan Hastalarda Kan Laktat Düzeyinin Prognoz Üzerine Etkisi. Osmangazi Tıp Dergisi. 2021; 43: 115-21.

16. Görmeli Kurt N, Orak M, Üstündağ M. The role of lactate clearance on deciding discharge in exacerbation of chronic obstructive pulmonary disease: Retrospective cohort study. J Surg Med. 2018 Mar 30.

17. Emektar E, Ramadan H, Yüzbaşığlu Y, Vural S, Coşkun F. Karbon monoksit zehirlenmelerinde, serum laktat düzeyleri ve tedavinin etkinliğinin belirlenmesinde laktatklirenslerinin kullanılması. Kırıkkale Üniversitesi Tıp Fakültesi Derg. 2017 Aug 31.

18. Ibrahim A, Bayramoglu B, Hokenek NM, Tekyol D. Lactate clearance during the first 2 hours after hospital admission: A useful biomarker for predicting 30-day mortality in patients with diabetic ketoacidosis. Int J Clin Pract. 2021 Jul 12; 75.

19. Fuernau G, Desch S, de Waha-Thiele $S$, et al. Arterial Lactate in Cardiogenic Shock: Prognostic Value of Clearance Versus Single Values. JACC Cardiovasc Interv. 2020 Oct 12; 13: 2208-16. 